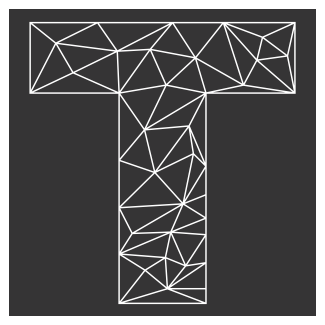

\title{
EMERGENCIA DE SUBJETIVIDADES POLÍTICAS EN TERRITORIO TÉRRABA: EL CONTEXTO DE LA MESA DE DIÁLOGO CON LAS POBLACIONES INDÍGENAS DE LA ZONA SUR DE COSTA RICA
}

Revista Trama

Volumen 7, número 2

Julio - Diciembre 2018

Páginas 27-50

ISNN-1659-343X

http://revistas.tec.ac.cr/trama
Emergence Of Political Subjectivities In Térraba Territory: The Context Of The Government Dialogue With The Indigenous Populations Of The Southern Region Of Costa Rica

Dr. Vladimir Mesén Montenegro ${ }^{1}$

Fecha de recepción: 13 de julio de 2018 Fecha de aprobación: 29 de agosto de 2018

Mesén, V. (2018). Emergencia de subjetividades políticas en territorio Térraba: el contexto de la mesa de diálogo con las poblaciones indígenas de la zona sur de Costa Rica, Trama, revista de ciencias sociales y humanidades, Volumen 7, (2), págs. 27-50.

DOI: https://doi.org/10.18845/tramarcsh.v7i2.3941
1. Profesor. Escuela de Ciencias Sociales. Instituto Tecnológico de Costa Rica, Cartago, Costa Rica. Escuela de Sociología. Universidad de Costa Rica. San José, Costa Rica. Correo electrónico: vmesen@itcr.ac.cr / vladimir.mesen@ucr.ac.cr 


\section{Resumen}

El presente artículo de reflexión es producto de la investigación doctoral del autor, y versa, como principal objetivo, en el análisis sobre la Mesa de Diálogo entre el gobierno de Costa Rica y las poblaciones indígenas de la zona sur entre los años 2014 y 2017, como espacio para dirimir conflictos en torno a la recuperación de tierras. La investigación fue de carácter empírica, basada en un trabajo de campo inspirado en la tradición etnográfica. En este sentido, se utilizaron técnicas como la observación participante, los relatos de vida y las entrevistas semiestructuradas, pero que construyó sus objetivos en función a problemáticas sociológicas. Así, por medio de la etonosociología, se visibilizan las disputas y resistencias que emprenden estas poblaciones indígenas, y se promueve el debate en torno a la manera en que se configuran como reformas culturales y sociohistóricas. A su vez, como parte de la discusión de los resultados encontrados, está la transición de sujetos indígenas a un sujeto político Térraba (en resistencia y recuperación de tierras) que luchan por la apropiación de su territorio y de su territorialidad, lo que permitió hilvanar entre las conclusiones más contundentes, la existencia de un proyecto de autonomía indígena denominado Bröran, y que transita de la subalternidad, al antagonismo, y finalmente, a la autonomía, que está latente como emancipación y resistencia a la imposición de proyectos por parte del Estado costarricense.

Palabras clave: movimientos sociales, ambiente, sujeto político indígena, proyecto hidroeléctrico, EI Diquís, Bröran, Térraba.

\section{Abstract}

The present article is a reflection the author's doctoral research, and it deals, as main objective, in the analysis on the "Mesa de Diálogo" between the Government of Costa Rica and the indigenous populations of the South zone between the years 2014 and 2017, as a space for settling conflicts around land recovery. The research was empirical, based on a field work inspired by the ethnographic tradition. In this sense, techniques such as participant observation, life histories and semi-structured interviews were used, but they built their objectives according to sociological problems. Thus, through the Etonosociology, the disputes and resistances undertaken by these indigenous peoples are make visible, and the debate is promoted around the way in which they are configured as cultural and sociohistorical reforms. On the other hand, as part of the discussion about the results found, is the transition of indigenous subjects to a political subject Térraba (in resistance and land recovery) struggling for the appropriation of their territory and territoriality, which allowed found between the most forceful conclusions, the existence of a project of indigenous autonomy called Bröran, and that transits from the subalternity, to antagonism, and finally, to autonomy, which is latent as emancipation and resistance to the imposition of Projects by the Costa Rican state.

Keywords: social movements, environment, indigenous political subject, hydroelectric project, El Diquís, Bröran, Térraba. 


\section{INTRODUCCIÓN}

En Latinoamérica son cada vez más visibles los movimientos políticos y socioculturales que reivindican los derechos de los pueblos indígenas sobre el territorio y la territorialidad. En un contexto de luchas contra el Estado y la sociedad civil como principales promotores de prácticas de invisibilización, así como de políticas de exclusión y violencia, se configuran las condiciones objetivas que promueven la constitución de procesos emergentes y emancipatorios, que tienden a promover transformaciones sociales y políticas significativas para estas poblaciones.

En el caso de Costa Rica, este contexto es el escenario de los conflictos socioambientales que se gestan con las poblaciones indígenas de la zona sur, frente a las propuestas del Estado costarricense por desarrollar proyectos de inversión pública en sus territorios.

A su vez, con la creación de la Mesa de Diálogo² entre el Gobierno de Costa Rica y los delegados indígenas de la zona sur, liderados por la representación indígena de Térraba, y con la presencia de dos instituciones observadoras, tales como, el Sistema de Naciones Unidas y la Defensoría de los Habitantes, se gestó el campo de condiciones para dialogar con base en una agenda propuesta por los representantes y discurre sobre los temas de territorio y territorialidad.

En ese sentido, la Mesa de Diálogo es una figura de carácter político del Estado para dirimir conflictos con las partes implicadas dentro de un espacio de conversación. Es un escenario de reunión entre personas, instituciones, organizaciones y otros actores para propiciar el diálogo sobre temas específicos que requieren consenso y acuerdos sobre determinadas situaciones. En este caso, dicho espacio se concentró sobre los temas de gobernabilidad y seguridad territorial, ya que de allí surgen las principales disputas entre los diversos actores implicados.

Por lo anterior, y como parte del objetivo general de la investigación, se analizó el carácter de las disputas por la apropiación del territorio y la territorialidad entre el Estado costarricense, la sociedad civil y las poblaciones indígenas de la zona sur, específicamente de la población Térraba en el marco de la agenda propuesta en la Mesa de Diálogo entre los años 2014 - 2017.

\section{EL ABORDAJE METODOLÓGICO}

La propuesta de la investigación partió de una metodología cualitativa desde la perspectiva fenomenológica. Lo anterior, en relación al esfuerzo por recopilar datos descriptivos a través de entrevistas, relatos de vida y observación participante, que permitieron tomar contacto con las formas de vida social, sus reacciones y/o el devenir de la cotidianidad, en relación al objeto de estudio, el cual se refiere a la emergencia de subjetividades políticas en las disputas por la apropiación del territorio indígena de Térraba, en el contexto de la Mesa de Diálogo Indígena.

Por lo anterior, la estrategia de investigación utilizó el enfoque etnosociológico (Bertaux, 1997), que parte de la experiencia social y política específica de la población indígena Térraba con relación a la agenda de la Mesa de Diálogo, en un esfuerzo por captar las lógicas propias del mundo social y de las situaciones particulares alrededor del territorio y la territorialidad.

Asimismo, interesó acercarse al mundo social de la población indígena Térraba en relación con el carácter de las disputas por la apropiación del territorio y la territorialidad expresados en la agenda de la Mesa de Diálogo. Por tanto, se hizo uso de técnicas como la observación no participante y participante, de la conversación o relatos de vida, así como de la entrevista no estructurada, del testimonio y del análisis de contenido.

\section{AUTONOMÍA Y AUTODETERMINACIÓN DEL TERRITORIO INDÍGENA TÉRRABA}

Las demandas por autonomía y autodeterminación del territorio y las territorialidades de las poblaciones indígenas en Costa Rica son un fenómeno social con posiciones antagónicas dentro de una sociedad multicultural, que detonan conflictos tangibles con actos de violencia y disputas por la apropiación del espacio físico y sociocultural, lo cual tiene un carácter eminentemente político.

2. La Gaceta N. ${ }^{\circ} 109$ — lunes 9 de junio del 2014. Formalización de la Mesa de Diálogo entre el Gobierno de Costa Rica y los Pueblos Indígenas de los Cantones de Buenos Aires y Pérez Zeledón. 
La capacidad de organización de las poblaciones indígenas de la zona sur de Costa Rica, como respuesta política por medio de una agenda denominada "Mesa de Diálogo", busca establecer según el Estado, lenguajes en común y entendimientos, lo que representa un hecho relevante para el estudio por parte de las Ciencias Sociales.

Lo anterior, en primer término, porque los conflictos de esta índole obedecen a procesos sociales, espaciales, culturales, históricos y políticos, que requieren ser explicados.

En segundo lugar, porque estos procesos permiten comprender las dinámicas de organización de las poblaciones indígenas y las contradicciones de un Estado excluyente de la diversidad, que promueve la aparición de conflictos sociales y culturales.

En tercer lugar, porque en la coyuntura de la Mesa de Diálogo, se muestran indicios de procesos emergentes que tienen un carácter emancipatorio, no solo a nivel local, sino que visibiliza redes globales de colaboración, apoyo y comunicación del movimiento indígena en Latinoamérica, lo cual tiene una gran riqueza analítica e investigativa para las Ciencias Sociales.

En ese sentido, las movilizaciones indígenas en la zona sur desde el año 2014 hasta el presente, por la recuperación de tierras en manos de no indígenas, tienen un carácter eminentemente político, así como elementos culturales que son acompañados por nuevos actores sociales como estudiantes universitarios, jóvenes, mujeres, así como una diversidad étnica de diferentes pueblos: Bribri, Boruca, Cabécar, Guaymi y Térrabas.

Por ejemplo, los procesos de recuperación de tierras de la Finca San Andrés, y más recientemente la finca llamada Potomac en territorio indígena Térraba, son de carácter ambiental, cultural, legal y productivo. Este proceso inició en el año 2015, y tiene como finalidad proveer a la comunidad de productos alimenticios, proteger el río Térraba, y mantener la resistencia frente a la Asociación de Desarrollo Térraba y el Gobierno Central, en relación con los proyectos de inversión en sus territorios.

Estas luchas indígenas de recuperación, son parte del conjunto de sentidos subjetivos, que modelan con mayor profundidad las subjetividades del sujeto político Térraba, que se proclama como poseedor ancestral de sus territorios, y que actualmente construye un proyecto de autonomía como vivencia cotidiana, que se basa en la defensa de su territorio, de sus prácticas cotidianas y culturales, y que se encuentran al margen de las decisiones o iniciativas gubernamentales, ya que dependen solo de sí mismos.

La autonomía del sujeto político Térraba es un proceso inacabado y no necesariamente es lineal o gradual, ya que contiene el pronunciamiento de su identidad cultural y étnica, que pretende el reconocimiento de esa identidad en las diversas subjetividades políticas que conviven paralelamente en el territorio, es decir, es también el reconocimiento de otras subjetividades políticas, tal como la Asociación de Desarrollo Térraba, que son subjetividades políticas más cercanas a los intereses de Estado, y que muestra la pluralidad de actores internos indígenas, también con distintos intereses.

Este proyecto de autonomía del sujeto político Térraba, pretende recuperar el territorio en términos de su uso productivo, así la Finca San Andrés está en un proceso de reforestación y aprovechamiento de los suelos para su producción, por medio de prácticas ambientales que permitan la sustentabilidad de las cuarenta familias que ingresaron a esta finca y se les denomina recuperadores.

Un ejemplo de los procesos que se están gestando en esta movilización de cuarenta familias Térrabas, es la construcción y mantenimiento de viveros, principalmente para contar con semillas de árboles autóctonos, tanto maderables como frutales, que posteriormente se irán sembrando.

De esta manera, el movimiento social indígena en Térraba, se destaca por ser una forma de acción colectiva que integra diferentes aspectos como la movimientos sociales constituyen una forma de acción colectiva que integra las propiedades empíricas desarrolladas por Tarrow (1997), donde en el caso de estudio, destacan los desafíos colectivos contra el gobierno, por ejemplo, la demanda indígena contra el Proyecto Hidroeléctrico El Diquís, ante el Juzgado Contencioso Administrativo, el 21 de marzo del 2011, que conllevan eventualmente en el año 2016 al cierre técnico del proyecto.

A su vez, los objetivos comunes de este movimiento social, que se concentran en la oposición por la invasión del Proyecto Hidroeléctrico El Diquís en territorio Térraba, se configuró como acciones colectivas que encuentran intereses y valores comunes como fue la expulsión del proyecto, y que activa la 
recuperación de tierras y la revitalización cultural de Térraba.

Así mismo, la constitución de una solidaridad comunal, en el reconocimiento de la comunidad de Térraba en relación con la presencia ilegal del ICE en territorio Térraba, así como el avance de los estudios básicos con obras significativas en términos de movimientos de tierra, perforaciones, accesos y caminos, y cambios en las dinámicas sociales y culturales de la población, tradujo el movimiento potencial en una acción colectiva de resistencia.

Los responsables de la movilización fueron principalmente las cuatro organizaciones comunales de Térraba (Rincón Ecológico Cultura Térraba; Asociación de Mujeres Mano de Tigre Térraba; Asociación Cultural Indígena Teribe; Asociación para la Defensa de los Derechos Indígenas de Térraba), quienes desempeñaron un papel de estimulación en la resistencia frente al Proyecto.

Finalmente, la acción colectiva de interacción mantenida en Térraba, se convirtió en un movimiento social cuando se muestran actividades colectivas que se mantienen frente a los antagonistas, tal como el proceso de resistencia contra el Proyecto Hidroeléctrico El Diquís que inició en el año 2011 y se mantiene hasta el presente año 2018, donde se han vivido diferentes momentos en los que el proyecto quiere resurgir por presiones e intereses políticos.

\section{EL CONTEXTO TEÓRICO: ALTERIDAD INDÍGENA COMO POSIBILIDAD DE AUTONOMÍA}

La realidad, en términos ontológicos, supone subjetividades en la percepción de cada uno de los sujetos sociales que la componen, por tanto, la organización social está compuesta por cada una de esas construcciones perceptivas de la realidad. Sin embargo, en la modernidad esta realidad ha sido construida por el proyecto hegemónico del sistema capitalista, creando el ideal del desarrollo, entendido como crecimiento económico y sobreproducción.

Dicho ideal sostiene la máxima a la que las sociedades del mundo deben aspirar, pero también delimita una línea hacia aquellos países y sociedades que son subdesarrolladas y que suponen erróneamente, deben transitar por el mismo camino para alcanzar un nivel de desarrollo. Tal como lo señala Harvey (2004), en que la larga supervivencia del capitalismo se puede abordar desde el análisis de los "ajustes espaciotemporales" y de su rol en las contradicciones internas de la acumulación de capital. En este sentido, existe una tendencia del capitalismo a producir crisis de sobreacumulación, que se expresan como excedentes de capital y de fuerza de trabajo, que coexisten sin que parezca haber manera de que puedan combinarse de forma rentable, a efectos de llevar a cabo tareas socialmente útiles (p. 101). 
De la misma manera, para Quijano (2000) en consecuencia, lo que está en debate acerca del "desarrollo" del capitalismo, es una doble cuestión, en primer término, se trata de las condiciones y determinaciones históricas que explican la tan diferente trayectoria del desarrollo del patrón de poder capitalista entre regiones y países en el mundo, en segundo lugar, si dadas las actuales características y tendencias mundiales de dicho patrón de poder - o en otros términos su "globalización" - es todavía realista para los latinoamericanos tentar el "desarrollo" capitalista en nuestros países, esto es, llevar a la práctica aquellas condiciones históricas que lo hicieron posible en otras áreas (Quijano, 2000, p. 3-4).

El discurso del desarrollo como máxima y aspiración universal, sujeta en cada una de esas percepciones de los individuos, finalmente compone la realidad objetiva que está fundamentada en el propio sistema capitalista, es decir, no se puede pensar Latinoamérica desde un lugar propio, porque está constituido por el saber euro-norteamericano.

El sistema capitalista promueve una única realidad social, económica, cultural, política e histórica. La cual, en esas condiciones, tiende a ser desigual, no solo por los aspectos materiales sino también por los subjetivos. No puede haber igualdad, así como no puede existir una verdad absoluta, sino las circunstancias objetivas y subjetivas en las cuales el sujeto tiene posibilidad de construir y construirse.

Esas condiciones son dadas por el neoliberalismo, tal como indica Quijano (2000), quien insiste que aunque a contrapelo de la reflexión dominante en este campo, es pertinente señalar que el estado-nación moderno (objeto exclusivo de esta discusión) es, en lo fundamental, producto de la distribución democrática del control de recursos de producción y de la generación y gestión de las instituciones de autoridad, entre los habitantes de un determinado espacio de dominación y en las condiciones del capitalismo. Se trata pues de un modo específico en que la sociedad capitalista asume determinadas características democráticas dentro de un dado espacio de dominación (Quijano, 2000, p. 4).

La sociedad capitalista moderna como organización social, tiene por tanto una construcción objetiva en términos históricos y sociales y también una construcción social y cultural, que parte de los elementos valorativos y subjetivos de los sujetos que la componen, para ese objetivo se requiere de la visibilización de la multiculturalidad.
No obstante, la diversidad y la diferencia son categorías invisibles en la sociedad moderna, donde la naturalización de las relaciones sociales es expresión del desarrollo histórico de la sociedad occidental, que tiene su génesis en la propia historia del capitalismo, tal como lo señala Mignolo (2013), donde la expansión del capitalismo occidental implicó la expansión de la epistemología en todas sus vertientes, desde la razón instrumental que está de acuerdo con el capitalismo y la revolución industrial, hasta las teorías de gobierno (la teoría política), pasando por la crítica al capitalismo y al Estado (Mignolo, 2013, p. 2).

En ese sentido la sociedad liberal industrial, indica Lander (2000), se constituye -desde esta perspectiva- no sólo en el orden social deseable sino en el único posible. En ese contexto, las diferentes sociedades de América Latina tienen una génesis en común, la conquista española; lo que implica que la constitución de una realidad objetiva esté marcada por los elementos históricos y sociales.

Esa sería- si se quiere- su ontología de la materialidad, en términos de una existencia objetiva. No obstante, así como en el espacio/tiempo original e inaugural de la primera "indemnización" de los sobrevivientes del genocidio colonizador, les convirtió en la primera población sometida a la "racialización" de su nueva identidad y de su lugar dominado en el nuevo patrón de poder (Quijano, 2011, p. 9).

En cuanto a lo anterior, los elementos constituidos en las bases de las sociedades en vías de desarrollo son parte de la fuerza hegemónica del pensamiento neoliberal, en tanto su capacidad de presentar su narrativa histórica como el conocimiento objetivo, científico y universal, y su visión de la sociedad moderna como la forma más avanzada pero igualmente normal- de la experiencia humana, está sustentada en las condiciones histórico-culturales específicas (Lander, 2000, p. 12).

La constitución de la ontología social está fundamentada en la dependencia subjetiva que tiene la materialidad, ya que es la condición ontológica de posibilidad; siendo sujeto y objeto de esa realidad que construye. Así, el marco de libertad que le ofrecen las posibilidades de las circunstancias con las que debe lidiar son limitadas y predestinadas.

Por tanto, no existe libertad alguna en las condiciones que presenta el sistema capitalista, ya que no existe posibilidad de escogencia, es decir, existe entonces una colonialidad del poder, en el que tanto 
América Latina y la población "indígena", ocupan un lugar basal, fundante, en la constitución y en la historia de la colonialidad del poder.

De allí, su actual lugar y papel en la subversión epistémica/teórica/histórica/estética/ética/política de este patrón de poder en crisis, implicada en las propuestas de la colonialidad global del poder y del bien vivir como una existencia social alternativa (Quijano, 2011, p. 10).

En la línea anterior, la colonialidad es producto de la modernidad, de manera que América Latina, desde el giro decolonial, pretende pensarse desde la construcción de su "propio lugar", distanciándose de la racionalidad instrumental del dominio sobre la naturaleza y la relación de medios-fines, propio del pensamiento eurocéntrico-estadounidense. Por lo que no es por accidente histórico que el debate sobre la colonialidad del poder y sobre la colonialidad/ modernidad/euro centrada, haya sido producido desde América Latina, así como no lo es, que la propuesta de "bien vivir" provenga del nuevo movimiento de los "indígenas" latinoamericanos (Quijano, 2011, p. 13).

La posibilidad de pensarse y constituirse desde el marco de libertad supone lidiar con las circunstancias históricas de la dependencia y reconocer las condiciones determinantes de colonialidad para América Latina, pero también implica reconocer que no se puede pensar abandonando el sitio en el que se es constitutivamente, en términos ontológicos.

Así, el paradigma hegemónico determina y limita el reconocimiento de las circunstancias en las que los sujetos están inmersos, en procura de construir un proyecto autónomo de organización social, donde el análisis del sistema moderno mundial introduce el colonialismo en escena, aunque más como un componente derivado que constituyente de la modernidad, puesto que aún no asume la "colonialidad", el otro lado (¿la sombra?) de la modernidad (Mignolo, 2013, p. 4).

De esta manera, las categorías de espacialidad en función del territorio son también construcciones heredadas por el sistema mundial moderno y supone que pensar el territorio y la territorialidad requiere comprender las condiciones de colonialidad en la región. En las cuales, las poblaciones "indigenizadas" bajo la dominación colonial, primero en América bajo Iberia y más tarde en todo el mundo bajo Europa Occidental, tienen como denominador común las perversas formas de dominación/explotación impuestas con la colonialidad del poder.
Por lo dicho anteriormente, la posibilidad de conocimiento en términos epistemológicos implicará conocer la propia vida de América Latina desde sus condiciones territoriales, socioculturales e históricas. A partir de esas realidades, se procura generar las rupturas necesarias que den cabida a reformulaciones propias de la existencia de las sociedades de la región, de sus vivencias, de sus existencias cotidianas y particulares.

El reto es considerar el carácter de esas rupturas ontológicas y epistemológicas heredadas de otros paradigmas, donde en la resistencia contra la herencia de otras paradigmas, las sociedades de América Latina han llegado a compartir aspiraciones históricas comunes contra la dominación, la explotación y la discriminación; producidas precisamente, con su paradojal ambivalencia: en la colonialidad/modernidad/euro centrada, la igualdad social de individuos heterogéneos, la libertad de pensamiento y de expresión de todos esos individuos, de la redistribución igualitaria de recursos, del control igualitario de todos ellos, sobre todos los ámbitos centrales de la existencia social (Quijano, 2011, p. 11).

De esa manera, la configuración de los temas que proponen las comunidades indígenas de la zona sur de Costa Rica, retoma la pluralidad de saberes para entablar un diálogo con el Estado, quien representa todas las condiciones históricas de la colonialidad del poder y del saber, y para plantear la posibilidad de desarrollar proyectos de infraestructura pública en sus territorios, no sin antes ahondar y resolver las temáticas prioritarias, como las de: territorialidad, territorio, políticas públicas y proyectos de ley.

\section{EL PAPEL DEL SUJETO POLÍTICO TÉRRABA COMO UN SUJETO DE CAMBIO}

El papel del sujeto político Térraba como un sujeto de cambio que se fortalece en el movimiento social, recupera fuerza en el tanto deben seguir enfrentando al Estado en sus diferentes iniciativas de proyectos gubernamentales en sus territorios. En ese contexto, el movimiento indígena Térraba, encuentra espacios de reivindicación para la constitución de formas de gobierno tradicional que les permita explorar autonomías indígenas, pero de forma territorializada, incluyendo de esta manera las diferentes etnias y pueblos indígenas de la zona sur, a través de los procesos de recuperación de tierras. 
Así mismo, la caracterización de procesos emergentes y emancipatorios, así como la evidencia de la constitución de sujetos políticos como expresiones de subjetividades indígenas, emergen como alternativas a la sociedad moderna capitalista, y, por tanto, como procesos decoloniales que muestran las posibilidades de mundos diferentes, inclusive, desde sus propias organizaciones sociales y políticas.

En ese sentido, se identifican nuevos movimientos sociales indígenas que surgen en la zona sur, caracterizados por la participación de diversidad de actores y actrices sociales, con posiciones políticas concretas, en relación con los cambios que quieren para sus territorios y la capacidad de articular agendas con los temas prioritarios para sus poblaciones, constituye uno de los hallazgos fundamentales de esta investigación.

Por ejemplo, referirse a la Mesa de Diálogo en Térraba como espacio que evidenció el movimiento social Térraba, es hablar también sobre la agenda propuesta por los pueblos indígenas de la zona sur y concretamente sobre el tema del territorio y las relaciones de dominación del Estado a través de la imposición de las asociaciones de desarrollo, tal como expone el dirigente indígena Pablo Sibar:

La Mesa de Diálogo es un tema que se las trae, hablar de la agenda que se propuso, de la gobernabilidad, del territorio, y hablar de este proceso pues a veces se dificulta, hay procesos, digamos Térraba fue reconocido por el estado de la ley de terrenos baldíos, 1939 y desde ahí ya somos un territorio inalienable, imprescindible $y$ no transferible y luego ha seguido, se ha seguido un proceso de reacomodo de decretos, leyes, luego de la ley del ITCO [Instituto de Tierras y Colonización] el estado mete como terrenos baldíos a Térraba y entonces nos quedamos como baldíos, sin embargo estas tierras nunca estaban baldías, nuestros abuelos y nuestros tatarabuelos que han vivido toda la vida en estas tierras verdad, y diay en el 77 se crea la ley indígena y en el 75 el Estado hace las Ilamadas asociaciones de desarrollo, en el 77 ya entones la asociaciones de desarrollo forman parte del territorio y en el 82 el Estado hace un decreto en donde dice que las asociaciones de desarrollo se convierten en el gobierno local del territorio, con una total imposición, nos imponen las asociaciones de desarrollo al territorio y no nos dejan ninguna expectativa digamos, ósea todo esto basado que en el 59 habían aprobado el convenio 107, y no era posible, este convenio hablaba de que las organizaciones indígenas teníamos que integrarnos a la sociedad dominante y entonces, pues no daba otra opción, en ese proceso nos quedamos, el tema de asociación de desarrollo que esa es la espina del territorio indígena ( $P$. Sibar, comunicación personal, 15 de octubre de 2016).

En esta línea, cabe destacar que las acciones colectivas en la población Térraba están enmarcadas, en lo que Tarrow (1997) definió como, las oportunidades políticas, y en su relación con la capacidad organizativa y los patrones culturales que los autodefinen, como parte de las expresiones de sus subjetividades políticas en tanto una etnia guerrera (Bröran), que se fortalece y constituye en la resistencia frente al PHED.

Al respecto, es importante destacar que se evidencia una mayor participación social de las poblaciones indígenas en el escenario nacional, lo que favorece un movimiento social que tiene como interlocutor a las diferentes organizaciones locales y dirigentes comunales, y no necesariamente a la figura de Asociaciones de Desarrollo Integral (ADI), ya que estas son entidades creadas e impuestas por el Estado dentro de territorios indígenas.

En ese orden de ideas, las estructuras de organización de los movimientos sociales indígenas en Costa Rica, son descentralizados, con apertura a diferentes y múltiples participantes, y no bajo el control de una figura particular o a la jerarquía de una organización occidental, favoreciendo la articulación con diferentes organizaciones y movimientos.

Por lo que, estos movimientos no responden exclusivamente a conflictos materiales o económicos, sino que tienen su núcleo en el ámbito de la cultura y los procesos identitarios; particularmente a procesos de conciencia, que permiten la consolidación de las bases para la construcción de las subjetividades políticas y sus expresiones, tal como, la recuperación de tierras o la resistencia a proyectos hidroeléctricos.

Es importante señalar que, en la percepción de representantes indígenas de otros territorios de la zona sur, como el caso del territorio indígena Salitre, la Mesa de Diálogo es una figura que surge puntualmente en Térraba:

Esa Mesa de Diálogo existió a raíz de todo ese conflicto que se dio entre Diquís y estos conflictos 
con Térraba, en este caso de nosotros participo un compañero Sergio Rojas, en esa Mesa de Diálogo, como representante del pueblo. Pero muchos de los compañeros indígenas de diferentes territorios, han querido hacer las cosas como diferente llevarlas pacíficamente, tener como un rol de trabajo, de acercamiento con el gobierno hacia nosotros, no exigirle lo que realmente nos corresponde como pueblo, entonces en ese diálogo no hubo posibilidad de compartir, la idea de nosotros es que no tenemos que negociar con nadie, el gobierno tiene que ver la cosa así como es, nada más, que estarle diciendo al gobierno, ellos lo tienen muy claro que cuales son las leyes $y$ en lo que tiene que proceder (J. M. Delgado, comunicación personal, 22 de octubre de 2014).

A su vez, para Marco Rivera director del Liceo de Térraba, la Mesa de Diálogo fue un espacio con intereses muy concretos:

Y no sé qué era la historia, pero yo sé la Mesa de Diálogo se deshizo y que ahora como que están llevando un protocolo, un protocolo para hacer una pre consulta. Cuando pasó Luis Guillermo, se llevaron a un chavalo de este Geimi, él es blanco, un indígena Maleku, entonces, yo creo que ese es el que ha estado haciendo el trabajo sucio del gobierno verdad. Trabaja en la casa presidencial, pero igual yo creo que ese chavalo ahí lo tiene para hacer el trabajo sucio. La Mesa de Diálogo, ellos dicen que no, pero es para el Diquís, porque, yo he ido en otras partes y he visto las represas que han hecho, y las injusticias que han hecho y diay la verdad es que nada que ver (M. Rivera, comunicación personal, 15 de julio de 2016).

Debido a la creación de la Mesa de Diálogo y particularmente de la presencia del Instituto Costarricense de Electricidad con sus intereses puntuales en el desarrollo de proyectos hidroeléctricos en territorios indígenas de la zona sur, se creó también un movimiento de los diferentes territorios, para hacer evidente que el tema del territorio y la territorialidad es fundamental para sus pueblos. Por ejemplo, tal como lo expone don Enrique Rivera:

En la Mesa de Diálogo no ha habido poder de decisión, si se dice bueno hagamos tal cosa, hay dos salidas una, como yo se lo plantee así en las leyes que nos amparan, una, tienes la opción de plantear al gobierno en la vía pacífica y para un dialogo importante, no de guerra, tener la opción de presentarle un plan, ok, en este plan señor le vamos a dar tiempo tres años para que nos recupere mil hectáreas y esta y esta que necesitamos, ahívamos a tener, 20030040 bueno vamos a darle, 40 hectáreas a cada paciente, entonces metemos tantas, pero tenemos una lista de gente que son tantos los que necesitan tierra y dentro de un año, otras mil, porque vienen las otras, eso tiene esa opción la vía pacífica, no violenta, y tiene la vía violenta, se violenta todo el montón de cosas, claro, con el derecho, aquí tiene el derecho y aquí tiene derecho (E. Rivera, comunicación personal, 22 de agosto de 2015).

Lo anterior, es parte de los elementos constitutivos del denominado sujeto político Térraba, entendido como el sujeto que emerge a partir de las acciones políticas, las cuales en el marco de la propuesta de Paul Almeida (2002), son constituidas desde las oportunidades políticas, que se concretan con el logro en la relación tiempo - oportunidad, de la lucha indígena Térraba contra el Instituto Costarricense de Electricidad (ICE), concretamente, con el cierre técnico temporal del PHED en el año 2016.

En este caso, el sujeto y las subjetividades de los pueblos indígenas continúan dirimiendo los conflictos con el Estado, ya que éste impone la aceptación de las leyes occidentalizadas hacia los pueblos indígenas, minando el reconocimiento de las diferencias culturales y su inserción en la vida de un país con una tradición histórica en la que se oculta y obstruye la multiculturalidad. No obstante, a lo interno de las poblaciones indígenas, se va consolidando el proyecto de autonomía indígena, al margen de la relación con el Estado y la sociedad civil.

De esta manera, la falta de reconocimiento de la diferencia y distinción étnica de los Térrabas por parte del Estado repercute en conflictos con la sociedad civil de los no indígenas, a los que se les permitió comprar terrenos indígenas y desarrollar proyectos de vida familiar, a la vez que actividades económicas y productivas, que consolidaron su presencia en territorios indígenas.

Los conflictos en las relaciones entre el Estado y las minorías étnicas se gestan en el tanto, las aceptaciones de las leyes estatales por parte de los pueblos indígenas suscitan también un reconocimiento de las diferencias culturales y su inserción en la vida cotidiana. No obstante, estas aceptaciones unilaterales no concluyen en el reconocimiento de la diversidad, como la aceptación de las múltiples formas de vivir y 
relacionarse con el territorio como parte de un todo (Zapata, 2010, p. 15).

Por ello, para los Térrabas, el Estado coacciona a las poblaciones indígenas mediante las Asociaciones de Desarrollo Integral, como formas de organización política que son antagónicas a las posibilidades de organización interna y tradicional. Al respecto, existe una percepción de la población Térraba, de que son organizaciones contrarias a sus intereses, y más bien, son cómplices de las instituciones públicas y demás entes que pretenden desarrollar proyectos de inversión en sus territorios (acueductos comunales, proyectos hidroeléctricos, actividades ganaderas o agrícolas externas), al margen de la consulta indígena y de los convenios internacionales.

En la línea anterior, para los entrevistados el proceso de apropiación del territorio indígena a la luz de estas asociaciones de desarrollo y demás instituciones del Estado, son muestra de la falta de apoyo por los intereses y necesidades indígenas.

Por ejemplo, desde la perspectiva de Pablo Sibar uno de los principales dirigentes indígenas de Térraba, la exigencia de que las poblaciones indígenas tenían que integrarse a la sociedad dominante coartaba de alguna manera la constitución de sus propias formas de organización y es por esto que crear organizaciones y/o asociaciones paralelas a la gubernamental, es una forma de constitución y reafirmación cultural y política.

En Térraba, pues una asociación de desarrollo manejada por la ley 3859 en donde no nos deja ningún espacio, la ley 3859 habla que las asociaciones son para desarrollo, yo no sé si entienden que son desarrollo o qué, pero eso es lo que dice la ley, entonces este, en este proceso diay nos quedamos ahí, en esta figura no indígena, una figura del Estado que impone a un territorio no indígena, y de ahí han venido un montón de broncas verdad, una junta directiva que reconoce a los no indígenas, una junta directiva que poco a poco ha ido destruyendo el territorio y hemos tenido que crear los espacios de una figura más acorde al derecho indígena, como por ejemplo el Consejo de Mayores Bröran, en donde es la figura que ha comenzado a trabajar de acuerdo al derecho constitucional del pueblo de Térraba verdad, defender el territorio, porque este territorio mediante la junta directiva a partir del 77 para acá el $80 \%$ está en manos de no indígenas verdad (P. Sibar, comunicación personal, 15 de octubre de 2016).
Por lo anterior, para algunos dirigentes indígenas de Térraba, la agenda de la Mesa de Diálogo en realidad es sobre los antecedentes expuestos, ya que no se puede entender la creación de un espacio de diálogo y negociación como el propuesto, sin antes atender una serie de temas históricos y conflictivos, que incluso han limado las formas de organización políticas tradicionales.

Inicialmente, las representación indígena de Térraba sintió como un logro la propuesta de la agenda para la Mesa de Diálogo en el año 2013, ya que la prioridad era resolver los conflictos sobre la territorialidad y de parte del gobierno se destinaron recursos para realizar varios estudios necesarios.

Hoy por hoy la cosa se agrava mucho más porque entonces la junta directiva reconoce a todos estos no indígenas, entonces esto se conoce en una situación muy difícil y ahorita estamos en una gran discusión, esa discusión de qué va a pasar y cómo lo vamos a meter. En el año 2013 y en el 2014 trabajamos en entablar la Mesa de Diálogo y con el gobierno con muchas consultas y de muchas actividades, hemos hecho marchas, caminatas y alguna serie de actividades que habíamos organizado a nivel nacional y se logra entablar la agenda de la mesa de dialogo en la región sur, participan seis territorios indígenas, cinco de Buenos Aires y uno de Pérez Zeledón, uno de los puntos en esa mesa de diálogo era la territorialidad, en esa territorialidad se maneja el termino de, bueno lo primero que hay que comenzar a hacer es la delimitación del territorio, porque a pesar de que existían las escrituras y tenía uno todas estas cosas, no existía una delimitación formal y se comienza con este proceso, con Salitre, se hace todo el proceso verdad de limitación de información de amojonamiento del territorio de Salitre y quedaban los otros cinco territorios, se logró en esa mesa de dialogo conseguir la plata para hacer los estudios en otros territorios, sin embargo como hubo cambio de gobierno eso se vino al traste (P. Sibar, comunicación personal, 15 de octubre de 2016).

En ese sentido, el cambio de gobierno frenó las iniciativas que se habían concretado con el tema del territorio y esto impidió que se siguiera avanzando en la agenda de la Mesa de Diálogo, ya que el nuevo gobierno cambió las prioridades que tenían los pueblos indígenas, en este caso el territorio, por impulsar el mecanismo de consulta indígena para construir el Proyecto Hidroeléctrico El Diquís. 
Por parte de Térraba era el representante el señor Manuel Villanueva, como integrante del Consejo de Mayores, el que viene a negociar el proceso que era el Consejo de Mayores Bröran, era él quien iba a estar al frente de este proceso, y se hizo, bueno se hizo bastante en este proceso, por lo menos había una línea de trabajo que duro un montón de años para llegar a la definición de las tierras, pero, por lo menos se había iniciado, uno de los grandes problemas como te digo fue que este gobierno no siguió con la mesa de dialogo. En este gobierno no se continuo con la mesa de diálogo, se han hecho algunos intentos, pero no hay una mesa de dialogo definida, porque la agenda la cambiaron, ahora el único tema es el mecanismo de consulta indígena, y ese proceso en este gobierno, el tema indígena cayó en manos de la Viceministerio de la Presidencia, ha sido el viceministerio de presidencia en la persona de Ana Gabriel (P. Sibar, comunicación personal, 15 de octubre de 2016).

A su vez, el devenir de la agenda de la Mesa de Diálogo quedó relegado en un solo punto, el que se refiere a la consulta indígena como único tema de importancia para el gobierno, lo que ha traído bastantes conflictos cuando llegan personeros del viceministerio a exponer los pasos para realizar la consulta indígena:

Es correcto, pero diay han pasado, ellos se han interesado, en la mesa de dialogo estaban cinco puntos como te digo, uno era gobernabilidad del territorio y el otro era el tema de consulta, este gobierno le ha puesto más énfasis al tema de consulta y entonces se ha estado trabajando en un protocolo de consulta que es el que se ha estado llevando a cabo verdad, sin embargo, pues aquí todavía no se ha podido hacer, no se ha podido hacer porque nosotros sostenemos que el proceso que tenga que ver en territorio indígena deben ser solamente indígenas, y no de personas no indígenas y ahí pues ha estado el estira y encoje que no hay manera (P. Sibar, comunicación personal, 15 de octubre de 2016).

Por lo tanto, el gobierno de Solís Rivera sustituyó la Mesa de Diálogo y desconoció la agenda propuesta por las poblaciones indígenas de la zona sur:

De los cinco puntos que había en la mesa de dialogo, ellos tomaron solo uno, el tema de consulta, entonces ellos decidieron hacer, en la mesa de dialogo pasada se hablaba en un protocolo de consulta que estaba, se venía trabajando, pero no era una prioridad de la mesa de dialogo por lo menos no era prioridad. Lo que si era la prioridad era el tema de tierras y gobernanza, con este gobierno se perdió y se perdieron dos cosas importantes en Térraba, ya se había logrado de la ADI se suspendiera y que no se podía hacer una asamblea de la asociación de desarrollo hasta que no se hiciera una verdadera depuración del padrón, esta depuración del padrón tenía que hacerla el Consejo de Mayores, sin embargo es interesante porque una vez entrando el nuevo gobierno, este diay también olvidaron esta directriz de DINADECO que Genaro convoco a una asamblea y se la avalaron y se retomó la Junta Directiva (P. Sibar, comunicación personal, 15 de octubre de 2016).

En este sentido, las expresiones de subjetividades políticas en Térraba continuaron, incluso en la recuperación de tierras, no solo frente a no indígenas sino ante la Asociación de Desarrollo Térraba, que para los demás grupos organizados y asociaciones de Térraba representan intereses de los no indígenas.

Mira en Térraba, la única finca que nosotros consideramos que es una recuperación es la que había comprado el INDERpagando unamillonada verdad, y nosotros le decimos una recuperación porque lo que se hizo fue tomar la finca para que la Asociación de Desarrollo no la tomara (...) es un proceso de compra verdad, nada más que hasta el día de hoy el juez no la ha entregado, el juez no la ha entregado y la ley como dice que se entregaría a la Asociación de Desarrollo, si esa finca se la entregara a la Asociación de Desarrollo, diay, este señor Genaro Gutiérrez la repartiría a los indígenas y no indígenas verdad, el haría una repartición general como ya hay evidencias, por ejemplo, en la finca Volcancito, que la repartió a una cantidad de gente no indígena, entonces por eso nosotros le decimos una recuperación, porque lo que hacemos es recuperarla pero no del no indígena sino de la $A D I$, entonces empezamos a recuperar la finca de la ADI para que el $A D I$ no haga fiesta con esa finca, ese es el tema que está ahí verdad entonces pues ahí es que vamos en esa línea ( $P$. Sibar, comunicación personal, 15 de octubre de 2016).

Debido a las confrontaciones internas entre las diversas organizaciones y la Asociación de Desarrollo Indígena de Térraba, se desarrollan acciones concretas de defensa de los territorios indígenas. No obstante, en el espacio de la Mesa de Diálogo, surgió polémica a lo interno de la población Térraba sobre la legitimidad de los representantes para negociar con el gobierno. 
Nosotros empezamos a dar la lucha aquí interno, se metían recursos de amparo y todos los perdíamos, eso era lo raro, porque mira, si la ley indígena, el articulo tres de la ley indígena que la tierra es inalienable, intransferible, imprescriptible, única y exclusiva para los indígenas que la habitan ¿Cómo va a llegar el "Diquís" a meterse a nuestra tierras? si el permiso dice que para que un proyecto se desarrolle en nuestro territorios, tiene que ser consultado y ¿Cómo es que todos los recursos los perdíamos? Entonces resulta que cuando nosotros vamos tomando la posición, y vamos, exigiendo, y exigiendo y exigiendo, pero entonces esta "Mesa de Diálogo" nosotros lo notamos, que estamos en la lucha, porque ahorita quienes están en la Mesa de Diálogo, es gente que no estuvo en la lucha (I. Rivera, comunicación personal, 24 de octubre de 2014).

Por consiguiente, el tema de los procesos de reapropiación del territorio y la recuperación de tierras de los indígenas trae consigo una significación local de lucha y subordinación histórica frente a las imposiciones estatales. Es importante recordar que entre los principales temas de la agenda de la Mesa de Diálogo se encuentra el tema de seguridad territorial.

Ante la ausencia del Estado, la gente ha buscado solución para recuperar las tierras. Se agudizó aún más cuando la gente no indígena - por ejemplo, mantienen una buena comunicación con el indio que hace lo que ellos dicen, pero cuando el indio tiene su posición ya no es amigo de ellos. Este presidente que estuvo en la asociación de desarrollo es uno de los que andaba montado con los ganaderos, y eso era uno de los problemas que veíamos en la población del manejo de la asociación (I. Rivera, comunicación personal, 24 de octubre de 2014).

El asunto de los ganaderos que se han apropiado de territorios Térraba es una de las molestias que expusieron los entrevistados. Este tema suscitó mayor organización indígena como unas de las acciones políticas inmediatas para asumir mayor apropiación de su territorio. Incluso fue uno de los temas que provocó antagonismos entre las organizaciones emergentes y la antigua asociación de desarrollo, ya que los que lideraban la asociación coadyuvaban intereses que eran no indígenas.

La resistencia Térraba por las prácticas agrícolas de la población no indígena en sus territorios y la disputa del mismo por demostrar la ilegalidad de su ocupación y usufructo, son algunos de los antecedentes que motivan la consciencia colectiva que va dando paso a organizaciones indígenas que, desde diferentes frentes, construyen claramente una lucha política.

Esta lucha se manifiesta en el caso de la presión de las diferentes organizaciones sociales que presionaron para que la $\mathrm{ADI}$ interpusiera una demanda contra el PHED ante el Tribunal Contencioso Administrativo de Goicochea, que prohíbe el ingreso y continuidad en forma pública de los trabajos del proyecto en el territorio indígena de Térraba.

Poco a poco hemos ido posicionándonos sobre nuestro propio territorio y con nuestras propias leyes, claro que no ha sido fácil. Yo estoy en contra del proyecto Diquís, inclusive hemos visitado lugares donde hay represas para ver a lo interno del territorio. $Y$ esto que nos dicen que si nosotros nos oponemos al proyecto estamos en contra de que el país tenga energía eléctrica, y eso no es cierto, nosotros sabemos que no es cierto. Eso es para vender, esa electricidad es para vender y no es para uso del país. ¿Qué significa construir esa represa en nuestros territorios? ¿Qué significa tener cinco mil hombres en nuestros territorios cuando nosotros apenas somos como seiscientos? Ahora teniendo acá gente trabajando, que no son de condiciones propias, porque hacen el trabajo de excavación y construcción, y nosotros que hacemos durante esa construcción. Nos pueden desaparecer (I. Rivera, comunicación personal, 24 de octubre de 2014).

Actualmente se mantienen confrontaciones directas entre las organizaciones sociales indígenas y los desarrolladores del PHED, ya que el Instituto Costarricense de Electricidad (ICE) en el mes de febrero del 2015, realizó presentaciones en el centro del poblado de Térraba, insistiendo en la importancia del proyecto PHED para el desarrollo del país, lo que generó reacciones de malestar y enojo por el irrespeto a las medidas cautelares, según expuso doña Isabel Rivera.

La lucha por sacar el Diquís ha sido algo terrible. Nosotros hicimos acá la lucha a lo interno, pero todos los recursos nos lo rechazaban, y nosotros insistíamos porque si el artículo 3 de la Ley Indígena dispone que las tierras en las jurisdicciones declaradas territorio indígena son inalienables, imprescriptibles, no transferibles y exclusivas de las comunidades indígenas que las habitan, el ICE no tenía nada que estar haciendo 
acá. Entonces el ICE decía que tenían permiso de la $A D I$, porque Genaro fue el que les dio permiso con cincuenta personas donde la mitad eran no indígenas. Hasta que decidimos que esa persona no iba a seguir haciendo cosas, sacamos el Diquís, lo quitamos de la ADI y nos empoderamos de nuestra tierra y de nuestras propias leyes (I. Rivera, comunicación personal, 24 de octubre de 2014).

De esta manera, la noción de subalternidad permite identificar la condición subjetiva de subordinación en el contexto de la dominación capitalista (Modonesi, 2010), ya que justo en el sistema capitalista es que se ha planteado el tema del desarrollo, suponiendo que la modernidad occidental debe permear a los diferentes grupos sociales y culturales para lograr un estado de mejoría material, espiritual y simbólico y el mismo debe aceptarse e incorporarse sin mayor sentido crítico.

Cuando el relator de las Naciones Unidas vino que fue cuando el Diquís salió, fue cuando el Estado se dio cuenta de lo que estaba pasando, porque nuestras denuncias nunca fueron escuchadas, $y$ por eso tenemos demandado al Estado. El relator dio un montón de recomendaciones como poner atención a la posesión de la tierra, más o menos lo que era equiparar las asimetrías, y poner atención a la gobernabilidad y el relator recomienda que se conforme una Comisión de Alto Nivel independiente del Estado e independiente de las poblaciones indígenas, y que sea conformada por especialistas de la OEA. Entonces se hizo la Mesa de Diálogo, y ahí hay gente de Térraba que en su momento estuvo de acuerdo con el Diquís. Pero en este momento está paralizada la Mesa de Diálogo, en este gobierno no ha estado funcionando. Ellos lo que hacen para bajarle lo que el relator dijo, entonces dicen que el Estado quiere un dialogo permanente y ahífue cuando les dijimos entonces que sin hablar del territorio y sin el proyecto de autonomía de los pueblos indígenas no había proyectos del Estado acá. Por eso es que ya no hay diálogo, porque era una cortina de humo, yo andaba en la Conferencia Mundial de Pueblos Indígenas de New York, y ahí fueron los indios también que les parece y esa Yoriko Kawisaba que es la representante de la ONU fueron a decir que la Mesa de Diálogo es algo así como la salvación de los pueblos indígenas, entonces ellos se enojan porque nosotros les decimos, los temas nosotros los pusimos en la mesa del gobierno ¿Y qué está pasando? ¿Qué efectivo en la práctica hay de esa Mesa sino hay diálogo? Por eso está esa lucha.
Si el Estado le interesa verdaderamente, ¿por qué solo están los pueblos de la Zona Sur? Claro, porque les interesa realizar los proyectos y no el tema indígena realmente. Tienen que estar todos los pueblos indígenas (I. Rivera, comunicación personal, 24 de octubre de 2014).

Expresiones de subjetividades políticas, como la toma de conciencia y reflexión de los entrevistados, como representantes de organizaciones indígenas que se configuran en términos históricos y constituyen elementos de conocimiento, donde la emergencia de dichas subjetividades se da a través de luchas concretas como la recuperación de tierras.

De esta manera, la principal lucha Térraba es la recuperación del territorio y de su territorialidad, por medio de la gobernanza tradicional que representa el Consejo de Mayores. Por lo que las organizaciones indígenas son vitales, en tanto se configuran como crítica a esas formas de dominación, que paradójicamente producen emancipación y fortalecen la idea de autonomía y que por tanto construyen subjetividad política en la población Térraba.

Venimos trabajando desde el año 2010 con la visión del derecho constitudinario, ósea la misma Ley Indígena en el artículo 2, los pueblos indígenas se regirán por sus propias estructuras comunitarias, entonces cuando yo veo eso $y$ veo la Asociación de Desarrollo digo hay una contradicción aquí, las estructuras comunitarias son lo propio que tiene el pueblo, y de ahí entonces trabajamos esta estructura verdad, comenzamos a trabajar este proceso y lo hacemos de tal manera que ha ido creciendo, donde yo sostendría que el Consejo de Mayores Bröran, es reconocido por el Estado, y por muchas instituciones del gobierno, por muchas instituciones inclusive de otros países verdad, hemos ido con este proceso, entonces vamos en este proceso muy lento muy despacio pero se va trabajando con afianzarlo para que aquí haya una figura propia del territorio (P. Sibar, comunicación personal, 15 de octubre de 2016).

A su vez, existe un grupo autodenominado como Tercera Vía, que aglutina a un grupo de jóvenes de poblaciones indígenas de la zona sur, primordialmente del territorio de Térraba. Esta agrupación ha logrado ingresar a espacios como las universidades públicas y desde allí formular proyectos de extensión y acción social para desarrollar actividades en territorios recuperados, como el caso de la finca San Andrés de Térraba. 
Para el año 2018, llevan a cabo un proyecto de agricultura orgánica (producción de cultivos orgánicos, producción de abonos orgánicos, emprendedurismo rural, control de plagas con extractos orgánicos, lumbricultura y buenas prácticas de agricultura).

El proyecto consiste en aprovechar el suelo de la finca recuperada llamada San Andrés en territorio Térraba y dedicarla al cultivo orgánico como alternativa de producción más limpia frente a los intereses y presiones de los no indígenas en sus territorios.

Es por esta razón que la propuesta de las poblaciones indígenas Térraba es tan relevante, en términos de su capacidad de articular una propuesta política en relación a la forma deseada de organización social y construcción de un proyecto de autonomía.

Este no es un tema cerrado sino abierto y heterogéneo, que promueve un debate a lo interno de las poblaciones indígenas, así como la exigencia de derechos adquiridos legalmente y que no son respetados por el Estado.

Bueno, se planteó hace poco, lo que pasa es que siempre se había tenido un Consejo de Mayores, lo que pasa es que el Consejo de Mayores en algún principio sucumbe con la entrada de la ADI y ya ahíhay algún indicio de que debe de existir alguna falencia, al menos, que no le permita subsistir en cuanto a esa otra política que al menos llega a los territorios (P. Nájera, comunicación personal, 25 de octubre de 2014).

Sin embargo, esa articulación histórica requiere en la lógica de la postura crítica, la posibilidad de que no exista un único mundo posible y que no sea solo un proyecto homogéneo en términos de singularidad política. En ese caso la autonomía de las poblaciones indígenas de la zona sur tendría un carácter dialógico que sería la base para las reformas deseables por ellos mismos, por ejemplo la postura del sector joven que plantea una "tercera vía".

Bueno, desde el primer punto, tenemos que partir, de que la idea no es de legitimar la autoridad tradicional, sino que tenemos conciencia de que si la autoridad tradicional, hay que tener cierta conciencia, si la autoridad tradicional tiene la potestad, debería también poder, ser expuesta a comportamientos políticos, de los mismos indígenas, para cuestionar los procesos que estamos llevando, ese planteamiento lo hemos estado compartiendo entre algunos compañeros, porque eventualmente va a haber una tercera vía siempre. La tercera vía es gente más joven, porque el proceso se enmarca, nuestro proceso indígena, hay que entender que tenemos dos clases de procesos que es uno solo, por así decirlo, este, tienen, uno que es territorial y luego una lucha política total, que es, cuando, la agenda política indígena prevalezca o pueda, mejor dicho, mantenerse, poder confrontar la agenda política de poderes, del gobierno, porque en realidad es una agenda impuesta y nosotros como indígenas lo que creemos, es que tenemos muchísimo que aportar al proceso nacional y que no se nos ha dado la posibilidad, y ahí es donde nace la tercera vía, la tercera vía, que nace, por ejemplo, en este caso, los indígenas del sur como ocho, como cinco pueblos indígenas (P. Nájera, comunicación personal, 25 de octubre de 2014).

Por otra parte, la reconstitución del Consejo de Mayores se ha ido consolidando y es en este momento la principal forma de organización reconocida por la población Térraba:

De acuerdo a la conversación con mayores de la comunidad, no es el Consejo de Mayores el que se puede convertir en el gobierno local del territorio, sino que el consejo de mayores es una figura de mucha potestad, de mucho poder, pero no gobierna, ósea si no que es una figura que más asesora, llama la atención y guía. El consejo de mayores se ve el que apapacha a la juventud, el que da consejos y no el que ordena y el que manda, sino el que guía en el proceso, de ahí nació la idea de hacer la base de datos con el Tribunal Supremo de Elecciones para definir los Térrabas, de los troncos familiares y entonces se trabaja en la base de datos conjuntamente con el Tribunal Supremo de Elecciones en todo este proceso (P. Sibar, comunicación personal, 15 de octubre de 2016).

No obstante, el Consejo de Mayores recupera dentro de la tradición Térraba el rol de un ente de consejería y guía en las decisiones comunales, así como de sabiduría tradicional que permite reconocer incluso los clanes familiares, lo cual fue recuperado por el Tribunal Supremo de Elecciones para construir un padrón o base de datos para llevar a cabo el proceso de consulta indígena, promovido por el gobierno de Solís Rivera.

Conviene subrayar, que las diferentes coyunturas políticas que matizaron diversos conflictos 
alrededor del tema de agenda de la Mesa de Diálogo, como la gobernabilidad territorial, incitaron formas de organización social y política por parte de los indígenas, donde los Térrabas articularon su historia de desposesión, sus patrones culturales y étnicos, con propuestas concretas de organización para el desarrollo económico y de luchas sociales, así como la configuración del Consejo de Mayores Bröran como entidad tradicional de gobernanza, para oponerse rotundamente a cualquier iniciativa o propuesta, hasta que se retome y se trabaje en la agenda propuesta por ellos en la Mesa de Diálogo.

Esta situación promueve que las poblaciones indígenas utilicen como manifestación de resistencia, la Ley de Origen como principio básico, que se rige por sus propias dinámicas culturales, sociales y políticas. Ésta brinda herramientas fundamentales para el diálogo recíproco de saberes, que ayudarían a fortalecer y explicar las acciones y actuaciones de los seres humanos frente a la naturaleza (Zapata, 2010), y que dan pie a la constitución de su autonomía indígena.

Al mismo tiempo, el gobierno central agravó las relaciones con los territorios indígenas de la zona sur, por concentrarse exclusivamente en uno de los temas de la agenda de la Mesa de Diálogo, que se refiere a la promoción de la consulta indígena para construir el Proyecto Hidroeléctrico El Diquís. Esta posición, omitiendo la historia de conflictos sociales entre el Instituto Costarricense de Electricidad (ICE) y los territorios indígenas de la zona sur desde la última década del siglo XX, por el aprovechamiento de la cuenca del Río Grande de Térraba.

Por esto, la propuesta del mecanismo de Consulta Indígena promovido por el Viceministerio de la Presidencia de Asuntos Políticos y Diálogo Ciudadano (2014-2018), no contaron con el apoyo de las organizaciones comunales indígenas de Térraba, pero pese a esta oposición, el instrumento fue aprobado por el Gobierno Central.

\section{VI.TRANSICIÓN DE LAS SUBJETIVIDADES A LAS SUBJETIVIDADES POLÍTICAS}

El tema de las poblaciones indígenas en Latinoamérica está enmarcado en discusiones sobre una serie de categorías y conceptos como: naturaleza, ambiente, desarrollo, política, gobernabilidad, entre otras.

Estas concepciones de herencia europea han repercutido en la manera en que las sociedades latinoamericanas se han organizado y el lugar desde el cual se sitúan a los diferentes grupos sociales y étnicos. En este sentido, las subjetividades han puesto de manifiesto que muchas de las creencias que modelan al mundo social, que se imprimen como inherencias de la naturaleza del socius y que en determinadas circunstancias encarnan consensos inamovibles, bien pueden ser el resultado de una historia profunda que pudo desmantelar de esas creencias cuanto tenían de naturalización o cuanto acarreaban de contradicción (Serna, 2012, p. 7).

En el caso de la población indígena Térraba, es en la configuración de las narraciones y las tradiciones orales emergen las diferentes maneras de ver y entender el mundo de lo cotidiano, así como de lo social.

Por ejemplo, la subjetividad es una producción simbólico-emocional de las experiencias vividas que se configuran en un sistema que, desde sus inicios, se desarrolla en una relación recursiva con la experiencia, no siendo nunca un epifenómeno de esa experiencia. La subjetividad es una cualidad constituyente de la cultura, el hombre y sus diversas prácticas, es precisamente la expresión de la experiencia vivida en sentidos diferentes para quienes la comparten, constituyendo esos sentidos la realidad de la experiencia vivida para el hombre (González, 2012, p. 13).

Esas producciones simbólicas, de significados emocionales dentro de un contexto de luchas y resistencias indígenas, la interacción con la modernidad desde los años 50 y el lugar desde la diferencia y distinción del indígena, hace que incluso las diferentes generaciones que crecieron con los relatos de un pasado con fuertes diferencias en Térraba, experimenten producción de múltiples subjetividades. La multiplicidad de subjetividades emerge de previo a poder denominar subjetividades políticas a las expresiones emergentes producto de las disputas por el territorio y las territorialidades. 
Así, la definición de subjetividad, como producciones simbólico-emocionales de la experiencia vivida por las personas y por las formas y prácticas definidas dentro de una organización social, hace que lo subjetivo sea irreductible a lo individual. Las personas y la multiplicidad subjetiva de los diferentes escenarios de su acción social definen la unidad inseparable de la subjetividad social e individual. La subjetividad social e individual mantienen relaciones recursivas, cuyas expresiones y efectos colaterales son simultáneos y diferentes, para cada uno de esos sistemas, constituyéndose recíprocamente a través de sentidos subjetivos diferentes (González, 2012, p. 13).

En la emergencia de las subjetividades políticas destacan las producciones individuales y sociales de la población Térraba, es decir, de los hombres y mujeres que, desde cada uno de sus lugares y biografías, experimentan los procesos de modernidad. Procesos que suponen la interacción con otras formas y valores sobre la realidad social y que particularmente desde el capitalismo, muestran interés por apropiarse por el territorio, es decir apropiarse y delimitar la propiedad privada.

Así, se entienden las subjetividades políticas en cuanto acción de reflexividad sobre lo político y la política que rompe con los determinismos, abre opciones para la actuación social, permite la emergencia de la novedad y con ello permite pensar que no hay individuos sujetos a poderes absolutos, ni al tiempo finito del ser particular, ni al tiempo infinito de la especie a la que pertenece. Por lo tanto, la esperanza, las posibilidades, las líneas de fuga, los puntos de quiebre, las rupturas de la tradición y la institución emergente sobre lo instituido son vías posibles para los colectivos.

\section{PROCESOS DE SUBJETIVACIÓN POLÍTICA EN LA POBLACIÓN INDÍGENA DE TÉRRABA}

En la subordinación se empieza a cuestionar la reproducción de las relaciones dominantes impuestas por la sociedad capitalista, y son reflexionadas por parte de las poblaciones indígenas en términos históricos, para tener un conocimiento que nutre esa subjetividad política que se traduce en luchas colectivas concretas, en este caso por la territorialidad. Además, que se configura como crítica y como confrontación a esas formas de dominación, que no pretenden otra cosa más que la emancipación y la idea de autonomía.

La autonomía en el caso del sujeto político de Térraba, se configura como la capacidad de articular formas de ver y entender el mundo, es ese conjunto imaginario colectivo e identitario, ya que es parte de la vida social, política y cultural, que permite explicar lo existente, y lo que se debe cambiar en términos políticos, para tener ese mundo posible y deseable.

Sin embargo, esa articulación histórica requiere en la lógica de la postura crítica, la posibilidad de que no exista un único mundo posible y que no sea solo un proyecto de civilización occidental. En ese caso, la autonomía de las poblaciones indígenas de la zona sur tendría un carácter dialógico que sería la base para las reformas deseables por ellos mismos, ya que estaría sustentado en las pretensiones de validez y no de poder.

En la siguiente tabla se plantea el análisis de los procesos de subjetivación política en la población indígena de Térraba, a partir, de las categorías de Modonesi (2010): 
Tabla 1. Análisis de las categorías de indagación sociológica marxista para el abordaje de los procesos de subjetivación política.

\begin{tabular}{|c|c|c|c|}
\hline $\begin{array}{l}\text { Categoría } \\
\text { analítica }\end{array}$ & Definición teórica & Construcción empírica & $\begin{array}{c}\text { Síntesis sobre la subjetivación } \\
\text { política de la población indígena } \\
\text { Térraba }\end{array}$ \\
\hline Subalternidad & $\begin{array}{l}\text { Expresión y } \\
\text { contraparte de } \\
\text { la dominación } \\
\text { encarnada o } \\
\text { incorporada en los } \\
\text { sujetos oprimidos, } \\
\text { base y, por ende, } \\
\text { punto de partida } \\
\text { ineludible de todo } \\
\text { proceso de conflicto } \\
\text { y emancipación. } \\
\text { El concepto de } \\
\text { subalternidad } \\
\text { se construye por } \\
\text { ende tratando de } \\
\text { entender tanto } \\
\text { una subjetividad } \\
\text { determinada } \\
\text { como su potencial } \\
\text { transformación } \\
\text { por medio de la } \\
\text { conciencia y la } \\
\text { acción política. }\end{array}$ & $\begin{array}{l}\text { Se refiere a experiencias de } \\
\text { subordinación, insubordinación } \\
\text { y emancipación surgidas de } \\
\text { relaciones de dominación, conflicto } \\
\text { y liberación. } \\
\text { No existe rebelión sin dominación. } \\
\text { Este binomio muestra que las } \\
\text { luchas indígenas se expresan en } \\
\text { tanto es el Estado quien ha ejercido } \\
\text { históricamente la dominación de su } \\
\text { territorio, incluso creando una figura } \\
\text { impuesta para la administración del } \\
\text { territorio, como lo es la Asociación } \\
\text { de Desarrollo Integral. } \\
\text { La formalización de la figura de } \\
\text { organización tradicional a partir } \\
\text { del Consejo de Mayores es una } \\
\text { medida que denota conciencia de la } \\
\text { población indígena Térraba frente al } \\
\text { papel de la ADI, a la vez que supone } \\
\text { una acción política explícita, que } \\
\text { busca mayor legitimidad en función } \\
\text { de su propia autonomía y no de la } \\
\text { determinación desde el Estado. }\end{array}$ & $\begin{array}{l}\text { Subalternidad indígena de la población } \\
\text { Térraba: } \\
\text { Las disputas por la apropiación de la } \\
\text { tierra y la territorialidad por parte de } \\
\text { las poblaciones indígenas y el Estado } \\
\text { son expresiones de subalternidad, } \\
\text { que a la vez promovieron procesos } \\
\text { de conciencia histórico-política en } \\
\text { territorios indígenas que dieron paso a } \\
\text { la expresión del sujeto político Térraba. } \\
\text { Las poblaciones indígenas son partes } \\
\text { integrantes, pero no totalmente } \\
\text { integradas de la sociedad civil. } \\
\text { Existe un proyecto de emancipación } \\
\text { de la población Térraba frente al } \\
\text { Estado, en la medida que se denota } \\
\text { en los procesos de resistencia frente } \\
\text { al Proyecto Hidroeléctrico El Diquís } \\
\text { y la recuperación de tierras, como } \\
\text { afirmaciones de conciencia por medio } \\
\text { de avances en su autonomía. A su vez, } \\
\text { existe una crítica de las miradas desde } \\
\text { arriba, desde el Estado-poder como } \\
\text { régimen establecido o como objetivo. }\end{array}$ \\
\hline Auto & $\begin{array}{l}\text { Una determinada } \\
\text { forma de } \\
\text { subjetivación } \\
\text { política que } \\
\text { se desprende } \\
\text { de prácticas y } \\
\text { experiencias de } \\
\text { liberación, forjadas } \\
\text { en el diálogo entre } \\
\text { espontaneidad y } \\
\text { conciencia. } \\
\text { En sentido marxista, } \\
\text { como principio } \\
\text { de ruptura política, } \\
\text { como expresión } \\
\text { de emergencia } \\
\text { poder de la clase } \\
\text { para sí y solamente } \\
\text { en segundo plano } \\
\text { y con mayor } \\
\text { ambigüedad } \\
\text { conceptual, como } \\
\text { una forma de la } \\
\text { futura sociedad } \\
\text { comunista. }\end{array}$ & $\begin{array}{l}\text { Las luchas indígenas de la población } \\
\text { Térraba son el resultado de un } \\
\text { proceso de construcción subjetiva, } \\
\text { es decir de una primera etapa } \\
\text { de emancipación, de salida de la } \\
\text { subalternidad. Por ejemplo, las } \\
\text { luchas por la recuperación del } \\
\text { liceo de Térraba, con el objetivo } \\
\text { de nombrar un director indígena } \\
\text { Térraba, así como también los } \\
\text { logros en la resistencia contra el } \\
\text { Proyecto Hidroeléctrico El Diquís, } \\
\text { que actualmente (2016) está en un } \\
\text { cierre técnico. } \\
\text { En ambos casos hay consciencia } \\
\text { en la población Térraba, de las } \\
\text { relaciones de dominación, a la } \\
\text { vez, que, de su condición de clase, } \\
\text { en este caso, de población étnica } \\
\text { excluida y relegada a los intereses } \\
\text { del Estado, primordialmente en } \\
\text { relación con el interés por explotar } \\
\text { los recursos naturales de sus } \\
\text { territorios. }\end{array}$ & $\begin{array}{l}\text { Autonomía indígena de la población } \\
\text { Térraba: } \\
\text { Las luchas indígenas en la resistencia } \\
\text { al Proyecto Hidroeléctrico El Diquís y el } \\
\text { proceso de recuperación de tierras, son } \\
\text { parte de la conquista de autonomía, } \\
\text { pero no necesariamente tiene que ser } \\
\text { circunscrito } \\
\text { a la emergencia del sujeto en un } \\
\text { contexto de dominación, es decir, la } \\
\text { relación entre el Estado - poblaciones } \\
\text { indígenas, se mantiene en la misma } \\
\text { relación de opresión del segundo } \\
\text { grupo, ya que las luchas se mantienen } \\
\text { en el tiempo y, por tanto, la relación de } \\
\text { dominación. } \\
\text { En el tanto se mantengan las } \\
\text { circunstancias del conflicto podría } \\
\text { convertirse como un ideal, en la } \\
\text { forma por excelencia de la sociedad } \\
\text { emancipada. } \\
\text { Por tanto, las luchas indígenas de la } \\
\text { población de Térraba son experiencias } \\
\text { de independencia y emancipación. }\end{array}$ \\
\hline
\end{tabular}




\begin{tabular}{|c|c|c|c|}
\hline $\begin{array}{l}\text { Categoría } \\
\text { analítica }\end{array}$ & Definición teórica & Construcción empírica & $\begin{array}{c}\text { Síntesis sobre la subjetivación } \\
\text { política de la población indígena } \\
\text { Térraba }\end{array}$ \\
\hline Antagonismo & $\begin{array}{l}\text { El concepto de } \\
\text { antagonismo en una } \\
\text { acepción subjetiva } \\
\text { que permite } \\
\text { reconocer, identificar } \\
\text { y nombrar el proceso } \\
\text { de conformación de } \\
\text { las subjetividades } \\
\text { en el conflicto, } \\
\text { la interiorización } \\
\text { o incorporación } \\
\text { de la lucha y la } \\
\text { insubordinación } \\
\text { como experiencias } \\
\text { y como factores de } \\
\text { subjetivación, de } \\
\text { diálogo entre ser } \\
\text { social y conciencia } \\
\text { social, de formación } \\
\text { de una "disposición a } \\
\text { actuar como clase. }\end{array}$ & $\begin{array}{l}\text { La Mesa de Diálogo propuesta } \\
\text { por el gobierno de Costa Rica con } \\
\text { las poblaciones indígenas de la } \\
\text { zona sur, surge en el contexto de } \\
\text { la resistencia frente al Proyecto } \\
\text { Hidroeléctrico El Diquís y al proceso } \\
\text { de recuperación de tierras de las } \\
\text { poblaciones indígenas de Salitre, } \\
\text { Cabagra y Térraba. } \\
\text { La Mesa de Diálogo es la expresión } \\
\text { del antagonismo expuesto por } \\
\text { Modonesi (2010), en relación con el } \\
\text { Estado - poblaciones indígenas. } \\
\text { De esta manera, la propuesta de una } \\
\text { agenda de temáticas prioritarias } \\
\text { para las poblaciones indígenas hacia } \\
\text { el Estado como impulsor de la Mesa } \\
\text { de Diálogo, mediante un decreto, } \\
\text { es también la causa de que la Mesa } \\
\text { de Diálogo no tuviera capacidad } \\
\text { operativa, es decir, la agenda de } \\
\text { las poblaciones indígenas y sus } \\
\text { prioridades, no son las mismas que } \\
\text { las del Estado. }\end{array}$ & $\begin{array}{l}\text { Antagonismo indígena de la población } \\
\text { Térraba: } \\
\text { El antagonismo Estado - poblaciones } \\
\text { indígenas se sintetiza en el devenir } \\
\text { de la Mesa de Diálogo, como un } \\
\text { mecanismo para dirimir los conflictos } \\
\text { y proponer espacios de negociación, } \\
\text { que simplemente no se ejecutaron, es } \\
\text { decir, el Estado no entabló el diálogo } \\
\text { propuesto. } \\
\text { El decreto para la formulación de un } \\
\text { Mecanismo de Consulta Indígena en el } \\
\text { mismo año } 2014 \text { es un proceso paralelo } \\
\text { que llega a sustituir en el gobierno de } \\
\text { Solís Rivera (2013-2017) la Mesa de } \\
\text { Diálogo del gobierno anterior, donde } \\
\text { prevalece el interés y la racionalidad } \\
\text { positiva moderna del Estado, como } \\
\text { propulsor del Proyecto Hidroeléctrico } \\
\text { El Diquís. }\end{array}$ \\
\hline
\end{tabular}

Fuente: Elaboración propia con base en Modonesi (2010).

Según el análisis de la tabla anterior, la constitución de subjetividades políticas en la población indígena Térraba se da a través de la subjetivación, en tanto proceso de constitución como sujetos y por medio de la cual se manifiestan las subjetividades propiamente.

En este sentido, los procesos de subjetivación política de acuerdo con Modonesi (2010) son articuladores de las subjetividades políticas, en la medida que se expresa en la población Térraba, la capacidad de organización y revitalización cultural, a partir de su pueblo originario, los Naso Teribes, en procura de rescatar los patrones culturales y la lengua madre.

Además, se reconoce en la población Térraba, como parte de las subjetividades políticas, las potencialidades como colectivo de articular sus preocupaciones y demandas, y desde allí generar estrategias para exigir que el Estado, dentro de ese campo de condiciones que pautan los pueblos indígenas de la zona sur, para proponer una agenta temática en la "Mesa de Diálogo", para valorar los proyectos de infraestructura pública dentro de sus territorios, lo cual indudablemente es una propuesta de diálogos interepistémicos, en el que subyace un proyecto de emancipación frente al Estado costarricense.

Según lo anterior, los conceptos de subalternidad, antagonismo y autonomía, se gestan en el seno de la reflexión marxista sobre el sujeto y la acción política, y constituye una constante que, de acuerdo con Marx, se prolonga a lo largo de los grandes debates del marxismo contemporáneo en la búsqueda de claves de lectura.

Por lo que es en el contexto de las relaciones de las estructuras de poder, es decir, Poder - Estado, que se encuentran una serie de luchas por lograr la promesa democrática de las hegemonías. Esto, en contraposición a otros saberes, visiones y mundos, que no son los de la modernidad occidental y que generan antagonismos, como por ejemplo con las poblaciones indígenas.

Así, el devenir de la historia de las poblaciones indígenas ha sido determinado por el lenguaje hegemónico, el cual construye y determina las 
categorías que lo atraviesan. En este sentido, se destacan las categorías como "reserva indígena" en referencia a las poblaciones indígenas y a los dirigentes indígenas, como las únicas formas de organización aceptadas por el Estado, que en el caso de Costa Rica son las Asociaciones de Desarrollo Integral, desde las cuales se establecen los únicos procesos de comunicación legítimos entre dichas poblaciones y los intereses del Estado.

Así, es en el sistema capitalista se ha planteado el tema del desarrollo, con el supuesto de que la modernidad occidental debe permear a los diferentes grupos sociales y culturales para lograr un bienestar material, espiritual y simbólico y el mismo debe aceptarse e incorporarse sin mayor sentido crítico como la única historia verdadera e irreductible.

De esta manera, los países colonizados sufrieron una total ausencia de políticas de derecho que legitimaran a sus poblaciones nativas, por eso en la mayoría de esas naciones, la política se expresó en el ideal de liberación, concretizado en la lucha por la independencia nacional (González, 2012, p. 13).

Esta visión tan reducida de la complejidad multicultural, pero sobre todo de la manera de entender y hacer política en Latinoamérica y en Costa Rica, repercute en la incapacidad de visibilizar y reconocer la legitimidad de las posiciones del Estado, frente a las posiciones, intereses y legitimidad de formas de organización tradicionales de los diferentes grupos indígenas.

Un problema grave en esos países fue que muchos de los propios libertadores se convirtieron en reproductores de la subjetividad social colonialista, generando poderes absolutos y centralizados. El poder político centralizado, caudillista y autoritario caracteriza hasta hoy la política en muchos de los países de América Latina, Asia y África, lo que favorece la fragilidad institucional de esos países (González, 2012).

Desde ese reconocimiento quizá sea más plausible discutir el tema de territorialidad, sin partir de que el mismo es nacional como plantea el Estado. Lo anterior en antagonismo al argumento de que la tierra es comunal, como indican los grupos indígenas. Es decir, se requiere de la capacidad de establecer diálogos entre los diferentes saberes de los grupos que existen y deben coexistir en el país.
De esta manera se forjaron diversas interacciones entre estos pueblos indígenas alrededor de las intenciones del Estado por materializar proyectos de inversión pública. Por lo que todo patrón de interacción social, es decir, todo régimen de prácticas colectivas características de la vida cotidiana se plasma y se concreta, siempre, en unas u otras "situaciones de interacción social con copresencia"; es decir, en unos u otros "encuentros físicos" -con continuidad espaciotemporal entre los hombres y mujeres concretos y reales, los "quién(es)", involucrados en el patrón de interacción social dado (Sotolongo, 2006, p. 136).

En función de lo anterior, estas interacciones han sido condensadas por las poblaciones indígenas de la zona sur como temáticas estratégicas que deben abordarse en procura de retomar (o iniciar) el diálogo con el Estado para el desarrollo de iniciativas institucionales en la zona, principalmente para generar una Mesa de Diálogo que permita establecer un marco general de "consulta indígena" para proyectos de infraestructura pública que se pretenda realizar en sus territorios.

Por lo anterior, es posible y pertinente analizar los procesos de subjetivación política, a nivel sincrónico, a partir del reconocimiento de combinaciones desiguales de subalternidad, antagonismo y autonomía -entendidas respectivamente como experiencias de subordinación, insubordinación y emancipación surgidas de relaciones de dominación, conflicto y liberación-y, al mismo tiempo, a nivel diacrónico, en función de un elemento ordenador que, tiñendo de sus colores a los demás, estructura y caracteriza la forma de las dinámicas de formación y configuración de las subjetividades políticas concretas en un momento o pasaje histórico (Sotolongo, 2006, p. 19).

De esta manera, el pueblo Térraba como un sujeto político, supone un nivel de autonomía que permite la emergencia de subjetividades que se configuran en las experiencias de la insubordinación y de gestación de ámbitos de independencia y emancipación (Modonesi, 2010, p. 26).

De ahí es que se conforma como el organizador de un posicionamiento político y cultural, en relación al binomio sobre dominación (hegemonía) y subalternidad, que facilita a estos pueblos articular los temas de desarrollo, ambiente, autonomía, territorio, territorialidad y políticas públicas, alrededor de las demás comunidades indígenas de la zona sur. 
Por tanto, la subalternidad es la expresión y contraparte de la dominación encarnada o incorporada en los sujetos oprimidos, base $y$, por ende, punto de partida ineludible de todo proceso de conflicto y emancipación (Modonesi, 2010, p. 30).

Por lo que la producción de una agenda para la Mesa de Diálogo muestra la subalternidad como expresión y contraparte de las concepciones y visiones desde una perspectiva occidental, alrededor de las poblaciones indígenas de la zona sur, que visibilizan el binomio de dominación y subalternidad para este caso, en relación a las propuestas de diálogo con el Estado costarricense.

Así, el antagonismo sería, en grandes líneas, el rasgo característico de la subjetivación conflictual, es decir la matriz de configuración de los aspectos subjetivos forjados al calor de la lucha y por medio de la experiencia de la insubordinación, en el cruce entre espontaneidad y conciencia (Modonesi, 2010, p. 83).

El tema del territorio también esboza la problemática de la compra y venta de terrenos ubicados dentro de las áreas declaradas como reservas por el Estado, según la Ley Indígena № 6172 del 20 de diciembre de 1977. Ya que se presenta la compra de terrenos indígenas por personas no indígenas, lo que conllevó a que en pleno siglo XXI no se tenga claridad sobre la posesión de la tierra y su legitimidad por parte de los no indígenas dentro de territorios declarados como reservas.

Estos antecedentes son parte de las experiencias de subalternidad del pueblo indígena Térraba, que sostienen los procesos de resistencia y negociación que se articulan en la Mesa de Diálogo, en el Mecanismo de Consulta Indígena y en la emergencia de organizaciones particulares que reivindican temas locales fundamentales por medio de acciones colectivas que constituyen movimientos sociales emergentes.

Al respecto, las categorías de subalternidad, antagonismo y autonomía son formas de nombrar, explicitar y delimitar una serie de problemáticas que circulan ampliamente al interior de los movimientos populares y del pensamiento crítico latinoamericano (Modonesi, 2010, p. 22-23).

Es claro que en reacción al territorio y la territorialidad se ha configurado un sujeto indígena con posiciones políticas definidas y también la necesidad de aprehender las subjetividades de estos sujetos emergentes. La conclusión política de este acercamiento es que las telarañas de la hegemonía no pueden ser desmanteladas por un simple y repentino acto voluntarista, sino que deben ser reconocidas y destejidas, paulatinamente, de la misma manera en que fueron tejidas, en el mismo terreno subjetivo que recubrieron (Modonesi, 2010, p. 36).

Por tanto, la hegemonía existente durante tantos siglos en contra de las poblaciones indígenas requiere procesos de asimilación, reflexión y consciencia, que a atraviesan las subjetividades de los sujetos y posteriormente, pueden manifestarse como subjetividades políticas.

\section{CONCLUSIONES}

En primer lugar, la Mesa de Diálogo es un escenario que mostró la relación orgánica entre el Estado, como expresión de la hegemonía (principal articulador de las relaciones de dominación) y las poblaciones indígenas de la zona sur; fungiendo como un disparador del proceso emancipatorio de la población Térraba y permitiendo la manifestación de su potencial transformador, por medio de la conciencia y la acción política, y que cada vez más, se expande a los demás territorios indígenas de la zona sur.

Esta conciencia surge de las subjetividades de los Térraba, la cual les permite organizarse políticamente en el campo de acción y representación de su territorio, en función y condición de sus circunstancias históricas, políticas, culturales, étnicas y sociales.

En la población existe un sentir de injusticia frente a los procesos de apropiación de sus territorios por parte del Estado y un sector de la sociedad civil. Sentir que se agudiza en medio de las reuniones de negociación de la Mesa de Diálogo, y que toma un carácter de resistencia en la relación de dominación con el Estado, en el momento en que se prescinde de la agenda para concentrarse en solo un punto.

El antagonismo Estado-poblaciones indígenas se fue sintetizando en el devenir de la agenda de la Mesa de Diálogo, como un mecanismo para dirimir los conflictos y proponer espacios de negociación, que simplemente no se ejecutaron. Es decir, el Estado no entabló el diálogo propuesto, ni tampoco aceptó la agenda formulada por las poblaciones indígenas.

El decreto para la elaboración de un Mecanismo de Consulta Indígena en el mismo año 2014 fue un 
proceso paralelo que llegó a sustituir, en el gobierno de Solís Rivera (2014-2018), la agenda de la Mesa de Diálogo del gobierno anterior. En éste, prevaleció el interés y la racionalidad positiva moderna del Estado, como propulsor del Proyecto Hidroeléctrico El Diquís (PHED).

Cabe destacar que la agenda de la Mesa de Diálogo, se construyó a partir de los intereses y preocupaciones de las poblaciones indígenas de la zona sur, quienes formularon una agenda con los temas prioritarios para consumar los espacios de diálogo y negociación, en función de su realidad y vivencias como sujetos indígenas.

El resultado de la Mesa de Diálogo fue su desarticulación, ya que fue irrespetada por el Estado y no mantuvo continuidad debido a los intereses gubernamentales por concretar el proceso de la consulta indígena, fundamentalmente para el desarrollo de proyectos de inversión pública.

Igualmente, en relación al tema de agenda de la Mesa de Diálogo, concerniente a políticas públicas y programas específicos para poblaciones indígenas, es vital reconocer el creciente desarrollo económico a partir de asociaciones y organizaciones locales que trabajan el turismo cultural o étnico, pero que se desarrollan al margen del apoyo estatal.

Para la población Térraba, son varias las luchas que fortalecieron sus posiciones políticas y una de ellas es la del desarrollo etnoturístico que inicia como una estrategia de apropiación y gobernabilidad de su territorio, la cual les permite tener una organización social importante para tomar decisiones sobre los procesos de desarrollo y resguardar sus fronteras territoriales.

La coyuntura en la que se desarrolla tanto la formulación como las reuniones de la Mesa de Diálogo, es el de una modernidad en la que está completamente inmersa la población indígena Térraba y el sujeto indígena de la zona sur, desde la perspectiva de la decolonialidad, lo cual evidencia que no hay modernidad sin colonialidad, tal como señala Escobar (2000), esta última es constitutiva de la primera.

Por lo tanto, la Mesa de Diálogo como manifestación del contexto de dominación y hegemonía del Estado, es un claro detonante en la conformación política del sujeto político de Térraba, a partir de los desencuentros evidenciados, suscitaron la puesta en escena de autonomía y la defensa por el respeto de su cultura, su relación con la naturaleza, desde una perspectiva sustentable, misma que implicaba un claro enfrentamiento con la posición del Estado, en donde prevalece la perspectiva de territorialidad como capital natural que debe ser aprovechado en términos de generar obras, proyectos o actividades, dentro de una lógica de acumulación de riqueza y aprovechamiento productivo de los recursos naturales.

El enfrentamiento de visiones e intereses, promovió que el gobierno en turno minara las posibilidades de dialogar, al suspender implícitamente la Mesa de Diálogo. Así como el silenciamiento de los intereses propios de las poblaciones indígenas en dicha mesa, promovió la emergencia de subjetividades políticas, mediante la búsqueda y consolidación de la autonomía política, a través del fortalecimiento de las formas de organización tradicionales, como: el Consejo de Mayores, la autonomía de hecho, la revitalización cultural y la emergencia de formas de organización que promueven el turismo cultural o étnico.

Estos a su vez, implicaron la recuperación de la lengua, las tradiciones orales y artes verbales, así como la percepción de las relaciones internas y externas como poblaciones indígenas. Así mismo, a partir de la consolidación de la autonomía de derecho, la apropiación de los convenios y acuerdos internacionales, así como la legislación nacional en materia de pueblos indígenas, fueron procesos de apropiación de herramientas vitales para defender sus derechos y enfrentar sus luchas indígenas.

En síntesis, la falta de consistencia por parte del Estado en la Mesa de Diálogo, promovió en las poblaciones indígenas de la Zona Sur, puntualmente en la población Térraba, el cuestionamiento sobre el respeto a los derechos humanos como minorías étnicas, lo cual favoreció su propia construcción de autonomía a través de la emergencia del sujeto político Térraba.

En segundo lugar, la constitución de las subjetividades políticas que se expresan en la agenda de la Mesa de Diálogo, constituyen alianzas no solo con organizaciones no gubernamentales que trabajan los temas de la ecología y el ambiente, los derechos humanos o la diversidad étnica, sino que favoreció los diálogos internos entre las diferentes etnias y territorios indígenas de la zona sur, es decir, los indígenas establecieron alianzas entre distintas poblaciones indígenas, creando así nuevas relaciones entre ellos, con frentes de lucha en común, tal como el de seguridad y gobernabilidad territorial. 
Estas alianzas alrededor de los temas del medio ambiente y territorios indígenas, entre diferentes etnias de la zona sur, constituye también, una expresión de nuevas subjetividades políticas que se cristalizan en el ámbito de sus intereses políticos en común, influenciados principalmente por el grado de madurez de las subjetividades políticas de la población Térraba. Esta población ha hecho frente a procesos de resistencia, que les dotó de experiencias múltiples y diversas, permitiéndoles construir diferentes procesos de identidad y respuesta frente a las presiones externas como el Proyecto Hidroeléctrico El Diquís, con un alto grado de capacidad adaptativa para expresar objetivos, intereses y amenazas a ciertos intereses en común.

A partir de la resistencia al PHED, se gestaron subjetividades políticas basadas en intereses comunes como población Térraba, donde destaca la apropiación e incorporación de influencias externas, como universidades, organizaciones no gubernamentales y movimientos estudiantiles en las luchas por su autodeterminación, tanto del territorio como de sus recursos, así como de sus procesos educativos y derechos como minorías étnicas. Luchas que fueron atrayendo, mediante el uso de las redes sociales, la atención de la comunidad local, regional e internacional.

Por estas razones, el sujeto político Térraba se configura en contraposición a los intereses del gobierno por ejecutar proyectos de inversión pública, es el antagonista de los intereses económicos capitalistas del Estado costarricense, en la medida que no permite que se ejecuten obras, actividades o proyectos unilateralmente, pues demandan autonomía sobre su territorio, y por tanto, entran en conflictos con las agendas estatales y las formas de vida que desean mantener, ya que reconocen la riqueza natural de su territorio.

Por tanto, el sujeto político indígena, rechaza la intervención estatal en su territorio, sobre todo por la agenda de la Mesa de Diálogo, en relación a la seguridad territorial y gobernabilidad del territorio, ya que no existe reconocimiento ni tampoco una adecuada titulación del territorio indígena de Térraba.

Así mismo, las subjetividades políticas que sustentan las acciones colectivas de la población Térraba, derivan de contextos cambiantes, inmersos en procesos sociales dinámicos, continuos e inacabados. También, se reconocen diferentes subjetividades políticas, que no representan grupos homogéneos dentro del territorio Térraba, y que más bien, se encuentran como actores sociales diversos y con contradicciones internas, donde el punto en común que los unifica es el de compartir posiciones subalternas, pero que se expresa en diferentes subjetividades.

Es importante indicar, que las subjetividades políticas atraviesan las vidas cotidianas y sus experiencias, las formas de ver y entender el mundo, y que no siempre estos procesos se dan por medio de la razón occidental, sino por la experiencia abstracta de las fibras emocionales de las personas, en relación con su entorno y su cultura.

Por lo que, la constitución del sujeto político Térraba, como expresión de las subjetividades de una alteridad indígena, que se pone en contacto con múltiples actores que visitan y se integran en la comunidad de Térraba, no se determina ni legitima, según una ley o política, sino en la experiencia de su autodeterminación, en la posibilidad de otros futuros, desde procesos internos y comunes, y en diálogo con la diversidad de otros saberes, inclusive los de la modernidad capitalista.

Finalmente, las disputas por la apropiación del territorio y las territorialidades de la población indígena Térraba, se expresan como el conjunto de rasgos y circunstancias en las que transcurren las luchas indígenas, se materializan en la consolidación de un movimiento social indígena de Térraba.

Este movimiento tiene su génesis en la constitución de subjetividades indígenas, que se expresan a partir de los desencuentros puestos en escena con la agenda de la Mesa de Diálogo, y que propicia la emergencia y emancipación del sujeto político Térraba, como manifestación socio histórica de las relaciones de dominación y subalternidad, que promueven un proyecto propio de autonomía.

Por tanto, desde una perspectiva marxista, la subalternidad es el potencial de transformación de la realidad social, por medio de la conciencia y la acción política. Es a su vez, la constitución de sujetos políticos, en tanto se logra conciencia de la realidad e identidad histórica y se toman posiciones frente a los actos en términos políticos. El lugar donde se identifica la emergencia de estos sujetos políticos son las poblaciones indígenas de la zona sur y en específico la población indígena de Térraba.

A su vez, las territorialidades Térrabas como expresiones de subjetividades políticas remiten incluso a las acciones colectivas alrededor de la defensa, reapropiación y reivindicación de luchas 
sociales por recuperar el territorio. Las interacciones y vínculos de las principales organizaciones de Térraba con su territorio se traducen en territorialidades que expresan ideas y visiones de mundo, saberes, prácticas y patrones culturales e históricos. Por lo tanto, muestra la heterogeneidad de pensamiento y acción de esta población indígena en cuanto al espacio físico que se comparte, pero que está lleno de significados y significantes distintos para cada uno.

Por ejemplo, la identidad de la población Térraba es constitutiva de sujetos políticos con proyectos conjuntos como la resistencia y recuperación de tierras, que a su vez se traduce en una dimensión emocional fundante, que proporciona sentimientos de inscripción y consenso.

Planteamientos tales como: ¿quiénes somos?, ¿cómo somos? y ¿quiénes queremos ser? se perfilan como elementos de construcción de su autonomía indígena, que van superando la dominación expresada por el Estado, a través de su interés por desarrollar proyectos de inversión pública como hidroeléctricas dentro de su territorio.

Lo anterior hace que el sujeto político Térraba, plantee procesos de conciencia, que supone la aparición del antagonismo como el espacio donde se gestan los conflictos en términos cognitivos y emocionales.

Es decir, es la interiorización e incorporación de las luchas indígenas de resistencia y recuperación del sujeto político Térraba que yace el reconocimiento de un ser social, su encuentro con una conciencia social y la disposición de actuar como clase étnica en un estado de opresión y dominación.

Esas interrogantes son parte del tejido social de Térraba, hilvanado por historias, anhelos, intereses, temores, proyectos de vida, deseos, aspiraciones, valores y patrones culturales como celebraciones y festividades.

Todos los procesos anteriores, en contradicción con los discursos oficiales sobre el ser indígena, relegado a reservas en territorios alejados y permeados por narrativas de subordinación a través del sistema educativo y de salud, político partidario, de la iglesia católica, del movimiento pentecostal, y los medios de comunicación hegemónicos que reproducen una historia oficial que no es cierta.

De esta manera, es clara la contraposición de la modernidad-colonialidad y sus implicaciones actuales en territorios indígenas como el caso de estudio, ya que trae a colación las configuraciones de la identidad y la relación con la idea de nación o país costarricense.

De esta manera los movimientos sociales indígenas expresan las subjetividades de identidades personales e identidades étnicas que dialogan con base en diferentes temáticas como el territorio, las territorialidades y la autonomía.

No obstante, la pertenencia a un grupo étnico es insuficiente para explicar las expresiones de subjetividades políticas como la resistencia y la recuperación de tierras.

Por lo que se debe considerar también el proceso de construcción y evolución de la conciencia del ser indígena, para resignificar su papel histórico y las tensiones propias de la modernidad, donde la búsqueda de la autonomía indígena trasciende de una acción solamente política a lo externo, sino que requiere una actitud colectiva que resignifique sus propias relaciones y formas de organización local, que en el caso de Térraba dan lugar a la creación del Consejo de Mayores Bröran.

Así, la emergencia de voces y experiencias en la población indígena de Térraba está en conflicto con la historia oficial de la modernidad, que acalla sus luchas y teme la constitución de las subjetividades políticas como detonantes de acciones colectivas y cambios sociales, que implique a su vez la emergencia del giro decolonial.

El proyecto de autonomía indígena de los Térrabas se configura como posibilidad de conformación del sujeto político, que, a través de sus luchas de resistencia y recuperación, se emancipa frente a las relaciones de dominación y dicta sus propias conductas y acciones sociales. 


\section{BILBIOGRAFÍA}

Almeida, P and Cordero A. (2017) Movimientos sociales en América Latina. Pp. 15-28 en Paul Almeida y Allen Cordero Ulate, Eds., Movimientos Sociales en América Latina: Perspectivas, Tendencias y Casos. Buenos Aires: CLACSO.

Almeida, P (2002). Los movimientos populares contra las políticas de austeridad económica en América Latina entre 1996 y 2001. En: Realidad, Revista de Ciencias Sociales y Humanidades, UCA, No 86, marzo abril del 2002, San Salvador, El Salvador.

Bertaux, Daniel (1997). Los relatos de vida. Perspectiva etnosociológica. Ediciones Bellaterra, España.

González R. (2012). La subjetividad y su significación para el estudio de los procesos políticos: sujeto, sociedad y política. En: Subjetividades políticas: desafíos y debates latinoamericanos. Claudia Piedrahita Echandía, Álvaro Díaz Gómez, Pablo Vommaro, compiladores. $1^{\text {a }}$ ed. -- [Bogotá]: Universidad Distrital Francisco José de Caldas, 2012. p. - (Biblioteca latinoamericana de subjetividades políticas). CLACSO.

Harvey (2004). El "nuevo" imperialismo: acumulación por desposesión. CLACSO. Buenos Aires. Argentina.

Lander, E. (2000) Ciencias sociales: saberes coloniales y eurocéntricos. En: La colonialidad del saber: eurocentrismo y ciencias sociales. Perspectivas latinoamericanas. Buenos Aires: CLACSO.

Mignolo (2013). Geopolítica del conocimiento y diferencia colonial. Revista Iberoamericana, Vol. LXIX, Núm. 203, Abril-Junio 2003, 401-415.

Modonesi, M (2010). Subalternidad, antagonismo, autonomía: marxismo y subjetivación política. - $1^{\text {a }}$ ed. - Buenos Aires: Consejo Latinoamericano de Ciencias Sociales (CLACSO); Prometeo Libros.

Quijano, Aníbal (2000). El fantasma del desarrollo. En: Revista del Cesla No. 1, Varsovia.

Quijano, Aníbal (2011). "Bien vivir": entre el "desarrollo" y la des/colonialidad del poder. En: Ecuador Debate 84, Quito.
Serna, D (2012). Prólogo. Subjetividades políticas: desafíos y debates latinoamericanos. Claudia Piedrahita Echandía, Álvaro Díaz Gómez, Pablo Vommaro, compiladores. - $1^{\text {a }}$ ed. -- [Bogotá]: Universidad Distrital Francisco José de Caldas, 2012. - (Biblioteca latinoamericana de subjetividades políticas). Consejo Latinoamericano de Ciencias Sociales - CLACSO.

Sotolongo (2006). La revolución contemporánea del saber y la complejidad social. Hacia unas ciencias sociales de nuevo tipo. CLACSO, Consejo Latinoamericano de Ciencias Sociales. Buenos Aires. Argentina.

Tarrow Sidney G. (1997). El poder en movimiento: los movimientos sociales, la acción colectiva y la política. Ed. cast.: Alianza Editorial, S. A., Madrid.

Zapata, Jair (2010). Espacio y territorio sagrado. Lógica del "ordenamiento" territorial indígena. Editorial Universidad Nacional.

\section{ENTREVISTAS A INFORMANTES CLAVE}

\begin{tabular}{|c|c|c|}
\hline $\begin{array}{c}\text { Manuel } \\
\text { Villanueva }\end{array}$ & $\begin{array}{l}\text { Consejo de Mayores avalado por el } \\
\text { Tribunal Supremo de Elecciones }\end{array}$ & $\begin{array}{c}13 \text { marzo } \\
2015\end{array}$ \\
\hline Pablo Sibar & $\begin{array}{l}\text { Asesor Consejo de Mayores avalado } \\
\text { por el Tribunal Supremo de Elecciones }\end{array}$ & $\begin{array}{l}15 \\
\text { octubre } \\
2016\end{array}$ \\
\hline $\begin{array}{l}\text { Paulino } \\
\text { Nájera }\end{array}$ & $\begin{array}{l}\text { Dirigente comunal / Rincón Ecológico } \\
\text { Cultura Térraba }\end{array}$ & $\begin{array}{l}25 \\
\text { octubre } \\
2014\end{array}$ \\
\hline $\begin{array}{l}\text { Isabel Rivera } \\
\text { Navas }\end{array}$ & $\begin{array}{l}\text { Dirigente comunal / Asociación de } \\
\text { Mujeres Mano de Tigre Térraba }\end{array}$ & $\begin{array}{l}24 \\
\text { octubre } \\
2014\end{array}$ \\
\hline $\begin{array}{l}\text { Elides Rivera } \\
\text { Navas }\end{array}$ & $\begin{array}{l}\text { Dirigente comunal / Asociación de } \\
\text { Mujeres Mano de Tigre Térraba }\end{array}$ & $\begin{array}{l}14 \\
\text { octubre } \\
2016\end{array}$ \\
\hline $\begin{array}{l}\text { Enrique } \\
\text { Rivera }\end{array}$ & $\begin{array}{l}\text { Dirigente comunal / Asociación } \\
\text { Cultural Indígena Teribe }\end{array}$ & $\begin{array}{l}25 \\
\text { octubre } \\
2014\end{array}$ \\
\hline $\begin{array}{l}\text { José Marino } \\
\text { Delgado } \\
\text { Rojas }\end{array}$ & $\begin{array}{c}\text { Dirigente comunal / Participante } \\
\text { proceso de recuperación de tierras } \\
\text { en Salitre }\end{array}$ & $\begin{array}{l}24 \\
\text { octubre } \\
2014\end{array}$ \\
\hline $\begin{array}{l}\text { Silvia Rojas } \\
\text { Delgado }\end{array}$ & $\begin{array}{c}\text { Maestra de Escuela / Participante } \\
\text { proceso de recuperación de tierras } \\
\text { en Salitre }\end{array}$ & $\begin{array}{l}24 \\
\text { octubre } \\
2014\end{array}$ \\
\hline Paolo Nájera & $\begin{array}{c}\text { Participante proceso de recuperación } \\
\text { de tierras en Térraba }\end{array}$ & $\begin{array}{l}25 \\
\text { octubre } \\
2014\end{array}$ \\
\hline
\end{tabular}

